\title{
Nota Introdutória \\ Critérios de Avaliação de Artigos de Investigação Qualitativa em Educação
}

Um dos primeiros desafios dos jovens investigadores surge com a escrita do primeiro artigo científico. Por vezes este desafio é idêntico quando o investigador, mesmo sénior, escreve o seu primeiro artigo de Investigação Qualitativa. Falamos de uma área bastante difusa o que levou a que alguns autores propusessem ferramentas (checklists) que auxiliassem os investigadores a escrever os seus artigos com a melhor estrutura.

Costa (2016) apresentou algumas dessas ferramentas: 1) COREQ - Consolidated Criteria for Reporting Qualitative Research constituída por 32 itens divididos (Tong, Sainsbury, \& Craig, 2007); 2) SRQR - Standards for Reporting Qualitative Research com 21 itens (Brien, Harris, Beckman, Reed, \& Cook, 2014) o ENTREQ - Enhancing Transparency in Reporting the synthesis of Qualitative Research (Allison Tong, Flemming, Mclnnes, Oliver, \& Craig, 2012) também com 21 itens; 4) o CASP - Critical Appraisal Skills Programme que possui várias checklists, destacando o Systematic Review Checklist e o Qualitative Research Checklist, ambas com 10 itens cada (Healthcare, 2013). No Quadro 1 apresentamos uma síntese destas Checklists e suas respectivas dimensões ou partes componentes. 
Quadro 1- Checklists e Dimensões

\begin{tabular}{|c|c|}
\hline Checklists & Dimensões \\
\hline \multirow{3}{*}{$\begin{array}{l}\text { COREQ } \\
\text { (32 itens) }\end{array}$} & Dimensão 1: Equipa de Investigação e Reflexividade (8 itens). \\
\hline & Dimensão 2: Desenho de Investigação (15 itens). \\
\hline & Dimensão 3: Análise e Resultados (9 itens). \\
\hline \multirow{6}{*}{$\begin{array}{l}\text { SRQR } \\
\text { (21 itens) }\end{array}$} & Dimensão 1: Título e Resumo (2 itens). \\
\hline & Dimensão 2: Introdução (2 itens). \\
\hline & Dimensão 3: Métodos (11 itens). \\
\hline & Dimensão 4: Resultados (2 itens). \\
\hline & Dimensão 5: Discussão (2 itens). \\
\hline & Dimensão 6: Outros (2 itens). \\
\hline \multirow{4}{*}{$\begin{array}{l}\text { ENTREQ } \\
\text { ( } 21 \text { itens) }\end{array}$} & Dimensão 1: Introdução (1 item). \\
\hline & Dimensão 2: Métodos e Metodologia (1 item). \\
\hline & Dimensão 3: Seleção e Revisão da Literatura (7 itens). \\
\hline & Dimensão 4: Avaliação e Síntese dos Resultados (12 itens). \\
\hline \multirow{3}{*}{$\begin{array}{l}\text { CASP (Revisão } \\
\text { Sistemática da } \\
\text { Literatura) } \\
\text { (10 itens) }\end{array}$} & Dimensão 1: Validade dos Resultados da Revisão (3 itens). \\
\hline & Dimensão 2: Resultados (2 itens). \\
\hline & Dimensão 3: Alcance dos Resultados (3 itens). \\
\hline $\begin{array}{l}\text { CASP } \\
\text { (Investigação } \\
\text { Qualitativa) } \\
\text { (10 itens) }\end{array}$ & Dimensão 1: Questões Preliminares. \\
\hline
\end{tabular}

Na sequência deste levantamento, elementos da equipa de coordenação do Congresso Ibero-Americano em Investigação Qualitativa (CIAIQ) e do International Symposium on Qualitative Research (ISQR) avaliaram o processo de avaliação deste evento (Costa, Souza, Souza, \& Mendes, 2017). A equipa tinha como questão de partida "Quais as motivações e sugestões de melhoria dos revisores e autores sobre o processo de avaliação dos artigos submetidos ao CIAIQ/ISQR?". Neste congresso seguimos a tipologia de revisão duplamente cega (double blind review), cada artigo foi avaliado por pelo menos três revisores. Dado que os melhores artigos do CIAIQ/ISQR são indicados para serem publicados em revistas, o objetivo foi o de compreender e melhorar o processo de avaliação da conferência, influenciando (in)diretamente a qualidade dos artigos escolhidos e submetidos às revistas. Aproximadamente 800 artigos foram submetidos na edição do CIAIQ2016 e cerca 700 artigos no CIAIQ2017. 
Foi aplicado um questionário aos membros da comissão científica e aos autores para avaliarem a qualidade e adequação do processo de avaliação da conferência. O questionário consistiu em 4 perguntas fechadas e 2 perguntas abertas. No total, foram recebidas 339 respostas (Costa et al., 2017). Neste contexto, os critérios de avaliação foram reformulados, discutidos e melhorados, sendo constituídos atualmente por 12 itens (Quadro 1). O modelo foi designado por Critérios de Construção e Avaliação de Artigos em Investigação Qualitativa (CCAAIQ) (Costa \& Souza, 2017).

Quadro 2- Dimensões, Questões Base e Questões Norteadoras do CCAAIQ

\begin{tabular}{|l|c|c|}
\hline Dimensões & $\begin{array}{c}\text { Questões } \\
\text { Base }\end{array}$ & $\begin{array}{c}\text { Questões } \\
\text { Norteadoras }\end{array}$ \\
\hline Questões e Objetivos de Investigação & 2 & 6 \\
\hline Fundamentação Teórica & 1 & 2 \\
\hline Metodologia & 4 & 12 \\
\hline Resultados e Conclusões & 4 & 10 \\
\hline Contribuições para o CIAIQ/ISQR e para a Investigação Qualitativa & 1 & 2 \\
\hline
\end{tabular}

Relativamente à Fundamentação Teórica, a questão base pretende aferir se a mesma é atualizada e articulada com o tema ou objetivos do estudo. As duas questões norteadoras questionam os revisores sobre "Quantos autores internacionais são citados como base do trabalho?" e "As publicações "clássicas" são citadas de forma articulada com outras publicações (por exemplo, últimos 5 anos)?”. Sendo o CIAIQ/ISQR um evento com foco na Metodologia foram definidas quatro questões base para esta dimensão. Duas delas questionam se "a opção metodológica é coerente com o problema e as questões de investigação" e se "os métodos e técnicas de análise de dados são adequados ao estudo". À semelhança da dimensão anterior estas questões, também, são "apoiadas" por um conjunto mais alargado de questões norteadoras.

Acreditamos que os critérios apresentados possam ajudar os revisores e que a sua estrutura confere aos investigadores-autores da área de educação (e não apenas) a possibilidade de produzirem artigos com mais qualidade.

Neste contexto, o Congresso Ibero-Americano em Investigação Qualitativa (CIAIQ) posiciona-se como um fórum extremamente relevante na àrea da investigação qualitativa e mista. O CIAIQ procura fomentar, através da interação, revisão, validação e da publicação de qualidade, alguns destes pressupostos de melhoria da qualidade da investigação qualitativa em várias áreas, e especialmente na educação.

O $5^{\circ}$ Congresso Ibero-Americano em Investigação Qualitativa (CIAIQ2016) decorreu de 12 a 14 de julho de 2016, na Universidade Lusófona do Porto, Portugal. A conferência envolveu autores de 29 países. Cada artigo foi submetido a um processo 
de revisão double-blind realizado por uma comissão científica composta por elementos altamente qualificados nas áreas científicas do congresso.

Este dossier temático da Revista Lusófona de Educação (RLE) contém oito selecionados pela comissão organizadora e científica do CIAIQ2016, de entre os melhores trabalhos de investigação da conferência relacionados com Educação. Os artigos deste dossier temático são originais, estando apenas publicados nas atas do CIAIQ2016 os respetivos resumos.

O primeiro artigo, Research choice: Pragmatism in conducting research about university-enterprise collaboration in the Vietnamese context de Thi Tuyet Tran, discute a escolha metodológica que a autora teve de realizar numa investigação sobre a colaboração entre universidades e empresas (UEC) e suas implicações para melhorar a empregabilidade de estudantes vietnamitas. O seu trabalho discute as problemáticas da apropriação da investigação qualitativa e sugere uma abordagem pragmática para o seu estudo.

O segundo artigo, Matriz metodológica para análise de comunidades virtuais de prática, de Antonieta Rocha e Alda Pereira, objetivou analisar comunidades virtuais na rede e o quadro metodológico adequado para se investigar estas comunidades. Apresentam também uma Matriz de análise de dados para identificar as comunidades virtuais de prática e os traços que as tipificam.

O terceiro artigo, Gnoses e Fazeres Interdisciplinares do/no Campo: a integralização de conhecimentos e práticas docentes na formação de professores da Educação do Campo, de Adriana Sadoyama, Leonardo Andrade, Maristela V. de Paula, Neila Borges, Vagner Rosalem e Geraldo Leal, tencionou dar a conhecer as respostas dos futuros professores acerca da formação integradora dos conhecimentos, numa abordagem interdisciplinar, a partir de como se sentem no processo e desenvolvimento dos saberes e fazeres no âmbito da perspectiva integradora do conhecimento.

O quarto artigo, A Interação entre pares: que lugar na avaliação do desempenho docente?, de Susana Oliveira Sá, analisou por meio do estudo de caso as vozes e narrações de professores acerca da proposta de substituição da avaliação do desempenho docente tutelado pelo modelo de supervisão entre pares, pela interação entre pares. Esta proposta revelou-se como uma boa prática no ensino reflexivo e instigador de melhoria na prática docente.

O quinto artigo, A promoção do Letramento Acadêmico em uma disciplina de escrita em contexto universitário brasileiro, de Bruna Vieira, assentou no objetivo de entender as práticas pedagógicas aplicadas numa Disciplina do Curso de Computação que no programa tem como finalidade o letramento académico dos alunos. A investigação teve por base o NEL (Novos Estudos do Letramento), perspetiva sociorretórica e análise e ensino de géneros. 
No sexto artigo, Significados das Avaliações do Ensino pelos Estudantes (AEE): Um Estudo Qualitativo na Educação Superior Brasileira, Maria Beatriz Bettencourt e Maria de Lourdes Sá Earp procuram respostas, nas vozes dos estudantes, acerca da avaliação do ensino e suas nuances. É interessante perceber como os estudantes refletem a desconfiança no processo de avaliação, a relação da avaliação institucional com a classificação da IES com o prestígio dos seus diplomas.

O sétimo artigo, Formação académica em metodologia qualitativa: Prática pedagógica em Psicologia da Educação de Ana Pereira Antunes, trabalhou com o ensino da metodologia qualitativa, no contexto da disciplina "Métodos de Investigação" no mestrado de Psicologia da Educação, numa universidade portuguesa. A autora focou a unidade de análise nas narrativas individuais dos estudantes que participaram desta disciplina.

O oitavo e último artigo desta edição intitula-se Percepções de interdisciplinaridade de professores de Ciências e Matemática: Um Exercício de Análise Textual Discursiva, de Valderez Marina do Rosário Lima \& Maurivan Güntzel Ramos, e procurou responder à seguinte questão de investigação: "Quais são as percepções de um grupo de professores que atuam na educação básica Brasileira sobre interdisciplinaridade em sua relação com aprendizagem em Ciências e Matemática?". O artigo revela que os participantes não entendem de forma clara o que é a interdisciplinaridade, ou seja, têm uma visão superficial e genérica do sentido pedagógico desta ação.

Finalizamos, agradecendo a todos os que de forma direta ou indireta colaboraram com o sucesso do CIAIQ2016 e com a produção deste dossiê temático, incluindo os participantes, autores, comissão organizadora e científica, apoios, equipa editorial, entre muitos outros. Através do seu interesse, participação e o primor pela qualidade e rigor do seu trabalho científico, agora publicado na Revista Lusófona de Educação, esperamos que possa ser promovida a expansão da investigação qualitativa numa área tão relevante como é a da Investigação em Educação.

\section{Referências Bibliográficas}

Brien, B. C. O., Harris, I. B., Beckman, T. J., Reed, D. A., \& Cook, D. A. (2014). Standards for Reporting Qualitative Research : Academic Medicine, 89(9), 1245-1251. http://doi.org/10.1097/ ACM. 0000000000000388

Costa, A. P. (2016). Processo de construção e avaliação de artigos de índole Qualitativa: possíveis caminhos? (Carta Editorial). Revista Da Escola de Enfermagem Da USP, 50(6), 890-891. http://doi. org/http://dx.doi.org/10.1590/s0080-623420160000700002

Costa, A. P., \& Souza, F. N. (2017). Critérios de Avaliação e Construção de Artigos em Investigação Qualitativa (CACAIQ). In A. P. Costa, F. N. de Souza, \& D. N. de Souza (Eds.), A prática na 
Investigação Qualitativa: exemplos de estudos (1ª, pp. 17-25). Oliveira de Azeméis - Aveiro PORTUGAL: Ludomedia.

Healthcare, B. V. (2013). Critical Appraisal Skills Programme (CASP). Retrieved November 25, 2016, from http://www.casp-uk.net/casp-tools-checklists

Tong, A., Flemming, K., Mclnnes, E., Oliver, S., \& Craig, J. (2012). Enhancing transparency in reporting the synthesis of qualitative research: ENTREQ. BMC Medical Research Methodology, 12(1), 181. http://doi.org/10.1186/1471-2288-12-181

Tong, A., Sainsbury, P., \& Craig, J. (2007). Consolidated criterio for reporting qualitative research (COREQ): a 32- item checklist for interviews and focus group. International Journal of Qualitative in Health Care, 19(6), 349-357. http://doi.org/10.1093/intqhc/mzm042

António Pedro Costa, Francislê Neri de Souza e Dayse Neri de Souza 